\title{
Negotiating Gendered Ageing: Intersectional Reflexivity and Experiences of Incongruity of Self-Employed Older Women
}

Work, Employment and Society 2022, Vol. 36(I) I0I-II8 (C) The Author(s) 2021

\section{(c) (i)}

Article reuse guidelines: sagepub.com/journals-permissions DOI: $10.1177 / 0950017021994489$ journals.sagepub.com/home/wes

(9SAGE

\author{
Elina Meliou \\ Aston University, UK \\ Oliver Mallett \\ University of Stirling Management School, UK
}

\begin{abstract}
This article analyses the experiences of self-employed older women. Developing an intersectional reflexivity approach, our analysis shows how older women negotiate their concerns in relation to gendered ageing and realize self-employment. Our study reveals three practices: 'Expressing the self', 'Exploring learning' and 'Embracing solidarity'. We contribute to the neglected intersection of gender and age in studies of work, and to an appreciation of the transformational potential of self-employment for older women.
\end{abstract}

\section{Keywords}

age, gender, intersectionality, reflexivity, self-employment

\section{Introduction}

As working lives are extended and more women remain in the workforce, the age-work exclusion experienced by older women has become a vital area of study (Jyrkinen and McKie, 2012). Studies of age and gender in organizational and professional settings have demonstrated how organizational cultures (Ainsworth and Hardy, 2008), labour market structures (Moore, 2009), age norms of retirement (Radl, 2012) and standardized transition patterns (Kohli, 2007) constrain women's late-career employment. Duncan and

\section{Corresponding author:}

Elina Meliou, Aston Business School, Aston University, Birmingham B4 7ET, UK.

Email: e.meliou@aston.ac.uk 
Loretto (2004) discuss 'gendered ageism' in reference to their finding that older women disproportionately experience ageist attitudes in employment compared to older men. Forms of age-work exclusion have left some older women to face precarious employment in low-paid, part-time work (McGregor, 2018). Nonetheless, in wider political debate, some view female participation in the workforce as part of the problems facing older men workers, leading to the further marginalization of older women at work and in the labour market (Ainsworth, 2002).

One proposed solution to the age discrimination and exclusion older women face in the workplace is for them to pursue self-employment (Lewis and Walker, 2011; OECD, 2019b). Self-employment, however, represents a potentially very different type of workbased experience 'reflecting unique, spatially and temporally situated combinations of the intertwining systems of age and gender' (Spedale et al., 2014: 1600). The limited research on self-employed older women focuses primarily on their hopes of entering self-employment (e.g. Tomlinson and Colgan, 2014), lacking an understanding of the realities of transiting and experiencing self-employment. Exploring the experiences of self-employed older women is therefore a lacuna this study seeks to address.

We draw upon the intersectional theorizing of McCall (2005) and Archer's (2003) work on reflexivity to develop the concept of 'intersectional reflexivity'. Archer argues that 'agents have to diagnose their situations, they have to identify their own interests and they must design projects they deem appropriate to attaining their ends' (Archer, 2003: 9). This perspective on reflexivity allows us to explain how choices are made within current circumstances, taking into consideration how the actions of actors are influenced by their intersecting positionalities over their personal, family and business life courses (Elder et al., 2003) and reflected in their personal biographies (Anthias, 2013). Drawing on a qualitative study of older women in the United Kingdom, we therefore ask: How do older women negotiate gendered ageing and realize self-employment in their situated context?

To answer this research question, we explore older women's reflexive struggles of gendered ageing, what their negotiation suggests about their resources and their personal experiences of self-employment within their individual contexts. We shed light on privileges and disadvantages within and across multiple cases of older women's experiences of realizing self-employment and identify three practices: 'Expressing self', 'Exploring learning' and 'Embracing solidarity'. In doing so, the study facilitates a deeper understanding of the experiences of self-employed older women, and the possibility of prescribing policy support that considers self-employment as 'a mechanism for combating social exclusion for marginalised groups’ (Lewis and Walker, 2011: 144).

\section{Older women and self-employment}

'Older workers' are defined in the UK as in their 50s and beyond (Department for Work and Pensions (DWP), 2017) and there is a significant policy focus internationally on the potential economic gains to be made by increasing workforce participation among this group (OECD, 2019a). Despite these policy initiatives, older workers remain marginalized in the labour market through exclusionary practices and discourses of deficit and decline. Age discrimination in recruitment, for example, persists and a recent large-scale 
field experiment found 'much stronger and more robust evidence of age discrimination against older women than against older men' (Neumark et al., 2019: 966).

One proposed response to ageism in the workplace is for those discriminated against, marginalized or excluded to pursue self-employment (Lewis and Walker, 2011). However, in seeking to explain the relatively low uptake of self-employment by older women (Office for National Statistics (ONS), 2018), Lévesque and Minniti (2006) argue that '[a]s we grow older, the opportunity cost of time increases [and as] a result, individuals become less and less willing to commit time to activities which yield returns over time, such as starting a new firm' (p.181). Such an argument makes a degree of sense through a neoclassical economic lens of older women as rational actors assessing the costs and benefits of their utilitarian actions. However, in treating age solely as an objective characteristic, this ignores how it may be socially constructed and 'socially, historically and culturally specific' (Moore, 2009: 656). Further, considering the returns in narrow, predominantly economic terms risks misunderstanding the reasons older women may have for entering self-employment.

Authors such as Hodges (2012), McKie et al. (2013), Tomlinson and Colgan (2014) and Walker and Webster (2007) locate key motivations in the transition from contractual, paid employment to self-employment by older women. These studies highlight the push factor of discrimination in employment driving older women towards self-employment where they identify greater possibilities of autonomy and personal success. In Tomlinson and Colgan's (2014) study of professional women considering the transition into selfemployment, they demonstrate how expressions of doubt and loss of assertiveness are intertwined with feelings of change and the consideration of self-employment as an appropriate trajectory with the opportunity for agency and independence. However, this study focused on older women considering entering self-employment for the first time. Their hopes at this point may not reflect the everyday realities of self-employment that they later experienced. For example, some of the hopes expressed by the women in Tomlinson and Colgan's analysis may not have been achieved given that, when the researchers followed up on their progress several years later, none of the women had been successful in establishing a sustainable business.

Notwithstanding the structural inequalities self-employed women face (Ahl and Marlow, 2012), it has been argued that being older may be an advantage, due to experience, resources and networks, and that the 'entrepreneurship domain appears somewhat liberated from the age-related discrimination compared to the domain of occupational employment' (Perenyi et al., 2018: 85). However, it is important not to assume that all older women have the skillsets and resources applicable to self-employment. Studies of social exclusion in entrepreneurship have shown how issues of race/ethnicity and class, among others, complicate those of gender and may limit certain opportunities (McMullin and Cairney, 2004). In turn, a marginal positionality constrains the accrual of human, social and economic capital, posing structural barriers to entrepreneurial activity. Some women may not have the financial independence, freedom from caring responsibilities or the experiences necessary to contribute to their human capital (Jayawarna et al., 2014). Lewis and Walker (2011) highlight the risks involved in self-employment, and the dangers of this as a 'policy panacea' for older workers, in financial terms but also in relation to the individual's health and well-being. 
The degree these barriers can be addressed varies greatly and may lead to very different experiences in self-employment for older women. We therefore adopt an intersectional approach to explore how older women with different life histories experience and seek to overcome discrimination or exclusion related to gendered ageing but also how they are able to access different opportunities for agency and realize self-employment.

\section{The life course and intersectionality}

To understand the experiences of self-employed older women, it is important not to simply consider people in a fixed state of being 'older' but to consider their experiences in the context of the life course. Life-course perspectives provide a way of making sense of the socially constructed nature of age. This understanding challenges the dominant view of growing older as a break with the past (Dumas and Laberge, 2005). It moves us towards an understanding of the different developments and changes in the body's functions over time. Elder et al. (2003) explain how a life-course perspective focuses on the 'social pathways of human lives, particularly in their historical time and place' (p.4). Key to life-course approaches are trajectories (e.g. careers, child raising) and transitions (e.g. graduation, a new job) and how these may differ between different generations but also cohorts differentiated by exposure to historical changes (possibly over briefer periods of time). For example, such effects may result from the demographic and pension changes that increasingly defer retirement. In the UK prior to 2010, a woman in her fifties was approaching the standard retirement age of 60 . Today, a woman of the same age has a longer, possibly undefined or uncertain period of working life ahead of her. There is a cohort effect for the women caught in the transitional phase of increasing retirement ages that they had not planned for (the UK's Women Against State Pension Inequality, or 'WASPI women') and a wider generational effect for those women who will spend their working lives without a standardized retirement age.

Intersectionality is an important means of exploring how the actions of older women are influenced by various intersecting structural and cultural contexts in which they are embedded over their life course (Elder et al., 2003). The positionality involved in intersections such as that of age and gender are not simply additive (ageism + sexism). Intersectional approaches have sought to treat, for example, race and gender not as mutually exclusive but to bring intersectional positions, such as 'black women', in from the margins (Crenshaw, 1991). An additive approach risks the inadvertent outcome that women's 'experiences of phenomenon, such as retirement, are interpreted in relation to assumptions based on men' (Krekula, 2007: 160): that is, to add to studies of selfemployed women other forms of experience or discrimination identified in relation to age (and often to older men).

McCall's (2005) work highlights the complexity of an intersectional approach that engages with the multidimensionality of experience, acknowledging the simultaneity of privilege and oppression and going beyond additive considerations of analytical distinctions. It understands age and gender as mutually constitutive and often intertwined with class or race or ethnicity, attending to the heterogeneity of experiences in relation to structural and cultural contexts while also solidifying the structural and cultural barriers (Anthias, 2013). It leads us to explore how individuals 'do' being an older woman in 
self-employment with more nuanced attention to what this positionality might involve in terms of resources: that is, resources that enable (or hinder) access to opportunities or actual material goods - and experiences of work.

However, little attention has been paid to age and gender in the literature, with Acker (2006: 445) suggesting that age, as a basis for inequality, is not 'as thoroughly embedded in organizing processes as are gender, race, and class'. Yet, more recent studies in organizations have identified that age represents an important form of inequality regime (McMullin and Dryburgh, 2011). Age does differ to other sources of inequality: while positions derived from gender, race or class are socially constructed and can change, they do not do so in the same way that age 'by definition alters throughout one's lifetime' (Choroszewicz and Adams, 2019a: 12). Nonetheless, Calasanti and King (2015: 196) argue that intersectionality is a valuable way to understand age 'because the ways in which people mark or perceive bodies as "old" vary with gender, race, class, and sexuality'.

Combining a life-course approach with intersectionality provides a valuable way forwards here. In their study of the professions, Choroszewicz and Adams (2019b) utilize such an approach to explore inequalities across cohorts and generations. Their analysis identifies 'how at key life-course stages, gender and age converge to confer privilege and produce disadvantage in professional workplaces within Western countries' (p. 3). Put simply, the life course of individuals is embedded in and shaped by socio-historical influences over an individual's lifetime. However, and importantly, older women's actions are not fully shaped by their structural and cultural contexts but also rely on the active agent (Clegg, 2006) creating subjectively interpreted courses of action within the structurally conditioned space of possibilities in which they find themselves. To engage with this agency, we develop an intersectional reflexivity approach.

\section{Intersectional reflexivity}

Archer's $(2003,2007)$ work on human reflexivity provides a valuable set of insights for understanding how actors, occupying various social positions within specific time/space frameworks (Anthias, 2013), navigate 'the opportunities and constraints of history and social circumstance' (Elder et al., 2003: 11). Archer (2003) argues that forms of reflexivity are the motor of social agency, enabling actors to satisfy their concerns with the intention of achieving desirable outcomes. When actors weigh up their actions, it is not pre-programmed but confirms reflexivity 'as the process mediating the effects of our circumstances upon our actions' (Archer, 2012: 6). Archer reminds us of the constellation of concerns that actors implicitly or explicitly inhabit in relation to their material, practical and social environments, which shape, and are shaped by, embodiment. These are related to one's 'physical well-being' in the natural order, 'performative achievement' in the practical order and 'self-worth' in the social order.

Ageing, as an experiential, embodied process, encapsulates older women's concerns, variously conditioning their practices. We reflect on who we are as 'embodied agents' (Crossley, 2006) and communicate to others through our embodied practices (Archer, 2003). Sociological research explores concerns with 'physical well-being' and how ageing may produce specific forms of discrimination such as 'lookism'. Lookism 'can be a 
part of covert control and aesthetic labour with embedded hopes and wishes for a "nice", sexualized and "ageless" physical appearance' (Jyrkinen and McKie, 2012: 65). Employees' looks have become an important feature in employment (Warhurst et al., 2012) and such concerns with physical well-being can affect self-worth.

Through differentiating between an 'on-stage' and 'off-stage' body, women have been found to 'describe their bodies with pride when they convey identity claims, and at the same time, talk about bodily changes with negative words' (Krekula, 2007: 166). That is, while there may be challenges faced - for example, through the health problems associated with menopause (Atkinson et al., 2015), the ageing body can remain (or become) a source of pride and pleasure. Studies of older women in the social gerontology literature, while acknowledging the negotiation of a 'normative minefield' (Thorpe, 2018: 211), have also reported findings that contradict the traditionally dour picture, including increased self-esteem and independence and the embracing of new possibilities and change (Cook, 2018). This is a potentially important issue for consideration of selfemployment because it has implications for individual motivation and the capacity to create a new venture.

Intersectional reflexivity reveals, thus, a sense of self that only emerges where the past meets the present and where social structures collide. Jones (2010: 122) notes that 'engaging in intersectional reflexivity requires one to acknowledge one's intersecting identities, both marginalized and privileged, and then employ self-reflexivity, which moves one beyond self-reflection to the often uncomfortable level of self-implication'. As will be seen, through intersectional reflexivity our participants engage with the incongruity experienced in their life course, evaluate their concerns and decide what to do in their attempt to both 'fit in' and 'stand out' (De Clercq and Voronov, 2009: 398). It is these 'gendered choices' (Risman, 1998: 297) that may lead to the realization of selfemployment as an important activity with the potential for emancipatory ends. However, to date these issues in self-employment have received only limited academic attention.

\section{Method}

The research was influenced by the biographical methods employed in life story research across sociology and adjacent disciplines (Bertaux and Thompson, 2006). Biographical methods allow us to gain insights into major social shifts by taking into account how novel experiences are interpreted by persons within groups and institutions. They encourage a reflexive understanding of the relationship between individual action and social structure. From a feminist framing, biographical interviews enable us to recognize the diversity and plurality of women's lived experiences and enhance their visibility (Lather, 1991).

The interviews reported here are part of a larger project (53 interviews) focusing on the lives of self-employed women. In this article, we examine a subset of the full sample: 10 older women who started their business at the age of 50 and beyond. Access was gained through a UK university and online women entrepreneurs' networks. Additionally, the 'snowballing' method was used to contact acquaintances of already participating women. Table 1 details the background of the 10 participants. Participants were all based in London and were engaged in a range of activities, encompassing early-stage and 


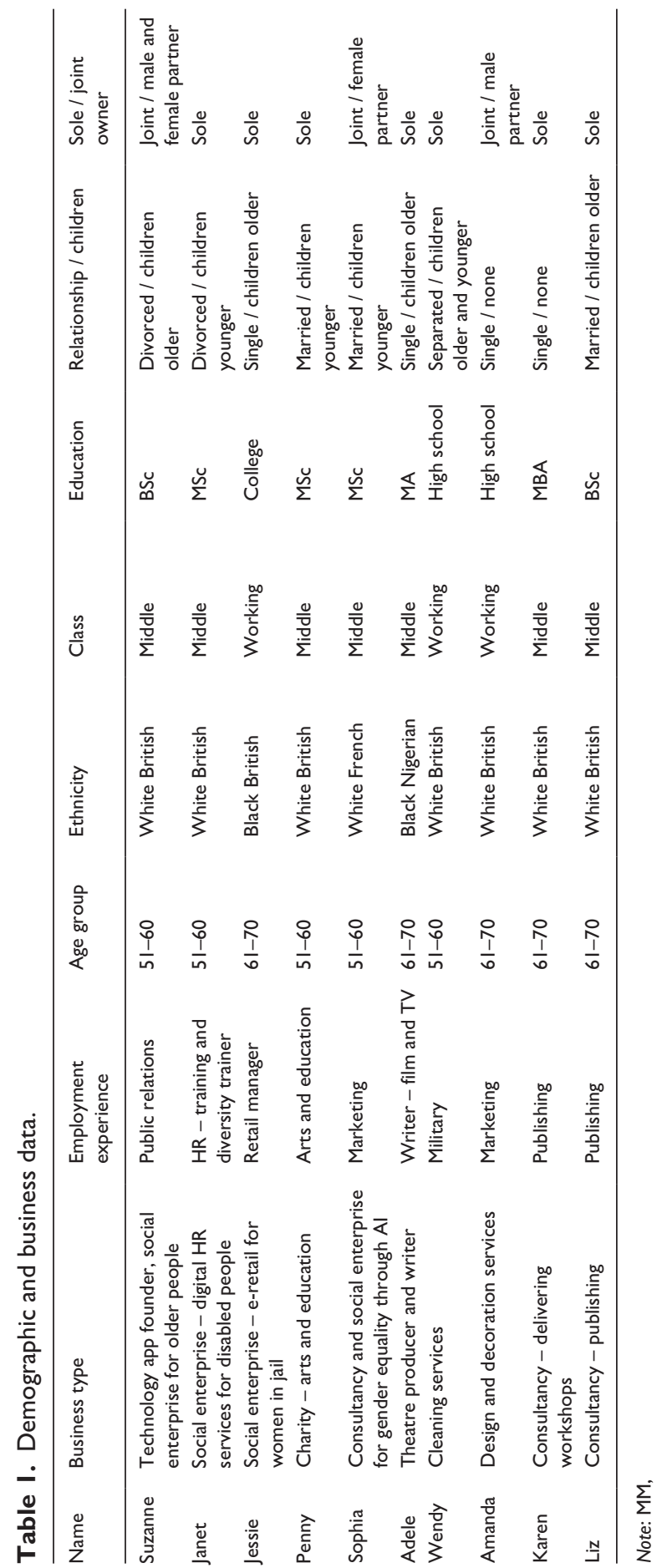


established businesses. Among the participants, there was a diversity of financial resources, educational backgrounds and employment histories.

Interviews were in-depth, lasting between one hour and two hours and 30 minutes and were recorded and transcribed verbatim. Biographical interviews tend to begin with an open-ended question such as: 'Can you take me through your life and employment, starting with information of your natal background, taking into account significant life experiences and employment transitions?'. Participants reflected upon themselves in relation to their work and life situations, explaining how they made decisions and their current understanding of employment and personal life in their situated context. To enhance the depth and complexity of the accounts, our interchange was informed by an analytical framework with suggestions of probes and directions for further discussions. This allowed us to expand upon key themes and ensure a degree of standardization among participants (Chamberlayne et al., 2002). In our initial analysis, we adopted an intracategorical approach (McCall, 2005) due to our analytical focus on a specific, relatively neglected intersection of gender and age in terms of self-employment. This acknowledges that older women share a common basis for their experiences by virtue of their position within social hierarchies and enabled us to identify thematic codes to articulate the broader structural and cultural dynamics in relation to gender, age and employment presented in each participant's biography.

We then asked how the primary themes could help us understand the projects of our participants and the justification of their actions, including realizing self-employment. We generated second-order themes that summarized recurrent patterns of concerns that influenced older women's transition to self-employment. In this stage, we accounted for variations through participants' positions and practices, comparing their actions across the analytical categories of ethnicity and class or other factors such as life situations, considering their differently weighted interactions. This is a synthetic and holistic process that brings the various pieces of the analysis together through a comparative, intercategorical approach (McCall, 2005), providing space for the connection and understanding across and within 'difference' (see, for example, Wright, 2016). In the final step, we identified three emergent practices that illustrate how older women navigated their concerns related to gendered ageing and experience the transition to selfemployment: 'Expressing the self', 'Exploring learning' and 'Embracing solidarity'.

Our findings illustrate how these practices are a feature of participants' intersectional reflexivity. Our focus was not to highlight the frequency of intersections or generalize participants' experiences. Some divisions can be more important than others in a particular context, while they may matter less in another context. Likewise, this article assumes that the context organizes the hierarchical relation of social categories. The data presented below are offered as a means of stimulating a discussion around the issues of gender, age and self-employment.

\section{Findings}

\section{Expressing the self}

Realizing self-employment was described by many of our participants as a positive and fulfilling experience or a way of 'Expressing the self'. This allowed them to satisfy and 
offset their concerns with physical, mental, emotional and aesthetic well-being associated with the challenges of gendered ageing. Studies of social gerontology identify positive consequences of autonomy and new opportunities for older people (Calasanti and King, 2015). A common thread in our analysis was that, having come through life transitions and events, such as incarceration or recovery from cancer, self-employment gave women a sense of being stronger emotionally and physically. It 'gave me a boost' as Sophia said.

Such narratives highlight the embodied aspects of gendered ageing as a prominent concern for our participants. Mobility difficulties, for instance, may prompt people to re-evaluate whether to stay in employment or to pursue alternative work. Janet, a British, white, middle-class, disabled, divorced woman with young kids explained how her personal life circumstances as well as becoming sick from a degenerative disc disease at an older age influenced her day-to-day and working practices. Her childcare responsibilities heightened her anxiety, encouraging reflexion about her future regarding work and home. Janet's condition restricts her from sitting and many workplaces are, therefore, unsuitable. She felt that the sustainability of the household could not depend on her, as 'if I couldn't work for any reason, we'd have no income at all'. Janet started an HR digital business that doesn't require physical presence and enabled her to work lying down:

I was getting divorced, selling a house, buying a house, raising two children single-handedly, my mother became disabled and I was her carer . . . When I was lying in pain, I felt very sorry for myself, but I also thought, 'I've got to spend this time wisely'. So, I drew up a business plan.

This was possible because her educational background and previous work experience in diversity training equipped her to put into practice her previous skills and knowledge, as well as to use her network of employers - supporting previous research on the importance of resources in entrepreneurship (Jayawarna et al., 2014). Janet's experience highlights how her actions to address her present concerns have been mediated by intersectional reflexivity, a feature of her reflexions on her social positionality and her life-course trajectory in identifying an opportunity. Such priority-setting has been identified as a key feature of reflexivity (Archer, 2007: 91). The analysis also shows the centrality of the gendered nature of caring directed to support family life, culturally reproduced as a 'natural' function in women's lives. Janet's story highlights the importance of the intersections of disability and class in shaping older women's experiences of self-employment.

Like Janet, Karen's case emphasizes her concerns with aesthetic well-being, in terms of the salience of looks in shaping experiences of work, affecting primarily female workers (Warhurst et al., 2012). Calasanti (2005) attributes this to the heightened importance of bodily appearance as a form of capital for women. Karen, a London-born, middleclass, white woman with more than 20 years' experience in the publishing industry was penalized from paid employment as the visible ageing body, in the form of grey hair, is seen as disruptive and unwelcome, transgressing social norms of youth (Ainsworth and Cutcher, 2008). To 'gain the business skills' and manage the transition to the marketing sector, Karen completed a 'grown up MBA' in one of the most prestigious business schools in the UK. 'Mulling over' (Archer, 2007: 91) her experience, Karen recalled her efforts, hopes and reflexive struggles in seeking to find a job in branding consultancy, but 'all they wanted was bright, young things'. These events and past experiences made 
Karen realize that the 'MBA was my big steppingstone . . . what became a disadvantage becomes an advantage ... K Karen started developing and running workshops on networking skills and selling them at universities, businesses and charities:

The fact that I had grey hair was an advantage because it meant I had gravitas. Now I can make jokes about it, which is wonderful. I can say to them, I don't like this and it's probably because of my grey hair ... nobody ever has asked me what my qualifications are for running workshops. I don't have any.

Despite the observation that the change to self-employment had been 'hard and uncertain', Karen explained that working for herself is 'hugely positive . . . it gave me the freedom which I liked, as I'm doing something I enjoy'. Expressing the self through the realization of self-employment was associated with the 'right look' and a sense of gravitas that engendered feelings of respect and trust. As in the case of Janet, Karen acknowledged that her financial security, not having familial responsibilities and a mortgage to pay were important. The shift from worries to respond and start a new business confirms that this move was not a passive process but reflects a process of 'deciding' (Archer, 2007: 91). It illustrates how intersectional reflexivity confirms how privilege and disadvantage coexist, generating 'surprising' career outcomes (Tatli and Özbilgin, 2012) that have the potential to navigate seemingly significant barriers to action in the context of multiple disadvantage.

\section{Exploring learning}

Some participants described how exclusionary organizational cultures, the changing nature of work due to technological advancements, or entering an unfamiliar industry affected their skills and legitimacy. Jessie recounted how her positionality, as a black, working-class, older woman, and her life situation, made her reflexive regarding future employment, as 'nobody is going to employ a woman of my age, with a criminal record, so I have to go back to self-employment'. In these cases, despite the 'push' factors involved, self-employment was nonetheless experienced as an exploration of growing and learning, enabling participants to seek personal and material contentment.

Bowman et al. (2017) highlight how ageing intersects with the deployment of different forms of capital that are valued within particular labour market contexts and carry symbolic power within them, motivating gendered and classed experiences of ageism. After more than 20 years in the consumer insights industry, Sophia, a French-born, white, middle-class woman, and mother of three young children, left a corporate career following the company's restructuring. She associated ageing with experience and learning, as 'I kept learning about myself, learning about the impact you have on others'. However, being 'too senior' didn't allow her 'to get them to see me doing another type of job'. Sophia recounted her efforts to find a paid job for almost two years and of her hope to continue learning:

I want to learn . . . if you read blogs you hear, 'We're going to need people to learn and learn again' . . . Every single time I've explained I do not necessarily want to do the same. I want to do data science because I've done all this mathematics and they've not changed, I've never managed to get that, never ever. 
Hallier (2001: 343) argues that older workers within professional fields are not dismissed because of ability but because of 'their capacity to question new management decisions and practices'. This suggests that older managerial and professional workers are marginalized because their accumulated institutional knowledge carries 'negative symbolic capital' (Spence et al., 2016: 6). During her interview, Sophia reflected on how she felt very insecure financially, insecure that 'I was ever going to get a job back', while seeking to care for her children. During this arduous process and through discussions with a French friend, Sophia was intrigued by the possibilities to 'de-bias the world with algorithms, with big data' and 'creating the opportunity' for herself to work in data science. One year later, they started a charity and a commercial business with the aim to advance gender equality using artificial intelligence. Here, origins and life trajectories enabled Sophia to combine a variety of resources at hand. We observe how ethnicity can intersect with experiences of gendered ageing, offering the potential for support and friendship on the basis of shared ethnic minority status, and may consciously be deployed to downplay disadvantages (Denissen, 2010), illustrating her intersectional reflexivity.

Similarly, Adele, a London-born, black, female, English literature graduate from a reputed UK university, explains how her positionality shaped her career prospects as a journalist, writer and theatre producer throughout her life course. Adele discusses the advantage of having the required background, skills and knowledge to advance her career, as 'there wasn't much competition in the pool as I was moving around African issues or black issues'. However, throughout her interview she reflects on the exclusionary culture of the film and TV sector, even for people "who have the necessary skills and education and qualification'. She discusses feelings of 'alienation', highlighting the interplay of privilege and oppression:

I wanted to grow, and, in my field, I was aware of the participation issue and it's still an issue.

There's no real space for African women, black women.

To mitigate the concern regarding the exclusionary cultures and satisfy her need to grow, Adele explored learning by starting her own theatre production business that relates to the concept of diaspora writing, as 'I'm in the African diaspora although I'm based here'. While our findings corroborate the importance of class in shaping experiences of older women realizing self-employment, they also complicate its meaning by showing how this experience intersects with race, highlighting the explanatory power of intersectional reflexivity.

\section{Embracing solidarity}

In some cases, the creation of a business was related to participants' social positioning. Embracing solidarity is underpinned by the broader concern of care and support for the self, and others, encapsulating actions of activism. Jones (2010) argues that intersectional reflexivity enables coalition activism and creates possibilities for alliance by prioritizing broad-based social issues that contribute to the oppression of many groups. This 'ethic of care' (Sevenhuijsen, 2000) is rooted in a commitment to human interdependence that is contrasted to the predominance of individualistic, masculine managerial practices, which 
overlook the concerns of women as well as feminist ways of seeing the world (Meliou, 2020). For example, becoming disabled in older age encouraged reflexion that led Janet to start a social enterprise that caters for the employability of disabled people.

Jessie, a black, working-class, London-born woman, with no formal education, started her current company - a social enterprise that 'helps women out of prison' - following 12 months in prison for conspiracy to defraud. Her story depicts personal concerns pertaining to lack of skills and knowledge, as well as legal and financial challenges. Throughout, Jessie reflexively invoked and contested her struggles as a self-employed older woman with limited resources. As our findings have demonstrated, participants' social positionality affects the capacity to apply class-structured privilege to self-employment and highlights how race and ethnicity complicate its notion for women of colour (Knight, 2016). However, Jessie expressed her persistence and resilience to make this work while at the same time feeling physically overwhelmed. She 'came up with the idea of inviting people to hear me talk about my experiences to get corporate sponsorship' to fund training for women. At the time of our interview, she had featured in national newspapers, TV shows and prison radio, and had collaborated with the Government to 'recruit undergraduates to be the next prison officers'.

Likewise, Suzanne, a white, American-born, middle-class, divorced, older woman transitioned in the technology sector, creating an app company. Her interview revealed the tension between the illusion of the (digital) enterprise discourse and the realization that she had 'no means of executing them'. Suzanne reflected on how older women are under more scrutiny, heightening the need to prove themselves and appear legitimate. She stressed how the media represents and always 'puts down older people'. This persistence and awareness strengthened her purpose and she started a social enterprise with the aim to change the media narrative about ageing, and offer alternative narratives regarding what it means to be legitimately self-employed or an entrepreneur:

It's all about anti-ageing and staying young, everything is framed against youth. It's all like, 'Wow, you look great for your age'. No, I just might look great full stop.

Two years later, Suzanne managed to pivot the business idea and raised capital for her company, mainly from 'people [of] my age'. She has been developing the social enterprise, albeit with difficulties, and, drawing from a position of a middle-class, older woman, she keeps challenging gender and age stereotypes and advocating for older people.

\section{Discussion}

This study set out to answer the question 'How do older women negotiate gendered ageing and realize self-employment in their situated context?'. Theoretically, it develops the concept of intersectional reflexivity to explain the experiences of incongruity of self-employed older women negotiating ageing experienced during their life course, leading to the realization of self-employment. Hence, our study enhances our understanding of the negotiation of age-work exclusion older women experience, as well as of the potential of self-employment as a form of emancipation for this relatively neglected group in self-employment research. The findings demonstrate the value of our intersectional reflexivity approach by 
emphasizing the potential for agency of older women in realizing self-employment to satisfy their concerns in relation to gendered ageing, taking into consideration how this transition is 'always embedded in life trajectories that give them distinctive form and meaning' (Elder, 1985: 31). In this way, the study not only elucidates the structural and cultural challenges that the context of 'gendered ageing' presents for our participants, but also highlights older women's reflexive abilities in negotiating these challenges (Archer, 2007), drawing from resources emerging from their distinctive positionalities.

The combination of McCall's (2005) intracategorical and intercategorical approaches for intersectional research design and analysis has enabled comparisons between those occupying more or less advantaged positions in relation to dominant social hierarchies, presenting thus a more holistic contribution to knowledge (McCall, 2005). This 'intersectional sensibility' (Crenshaw, 1991) has usefully revealed the heterogeneity in older women's experiences and actions on the basis of class, ethnicity, race and ability/disability. Our study illustrates how, at the intersection of gender and age disadvantage, older women can experience self-employment as empowering in achieving their career and personal goals.

Our analysis expanded on this by identifying three practices through which self-employment can be realized: 'Expressing the self', 'Exploring learning' and 'Embracing activism'. This is important because it shows how self-employment for older women can be a 'social change activity' (Calás et al., 2009) and a means for older women to overcome social and physical changes. Where this is successful, our findings demonstrate how selfemployment can provide a powerful means by which women achieve self-esteem, independence and change. We therefore argue that belonging to multiple disadvantaged and excluded groups does not always translate into multiple forms of disadvantage, supporting research on social gerontology (Calasanti and King, 2015). Our study extended intersectional research on gender and age in self-employment, by illustrating how individuals seek to transcend disadvantage by drawing on their intersectional reflexivity, extending research on intersectional analyses of otherness (Özbilgin and Woodward, 2004).

Our findings have important implications for policy action. Lewis and Walker (2011) list the myths on which self-employment for older people is promoted: that all small businesses contribute to the economy; that older people have appropriate skills and resources; and that self-employment will be a rewarding experience. While our participants talked about realizing self-employment as a way of achieving autonomy and selffulfilment, allowing them to negotiate the constraints of gendered ageing, they also described the challenges of creating and sustaining a new business. It is thus important to reinforce the evidence that, for many, the experience of self-employment is one of self-exploitation and struggle. We do not suggest self-employment for older women is a panacea; numerous studies have shown the exclusion and discrimination self-employed women face in growing and sustaining their business. Nonetheless, gaining a deeper understanding into the potential for empowerment through forms of intersectional reflexivity remains a powerful set of insights that we hope can act as a partial corrective to the discourses of deficit and decline.

The experiences of ageing described here may hold relevance for women in similarly economically developed countries or political contexts as the UK. In countries such as New Zealand, Australia, USA, and across Europe and the UK, people born after the Second World War are ageing under different contexts compared to previous generations. This is 
consistent with Archer's (2003) intensified role of structural and cultural contexts that heighten the need for reflexivity. We also note that, while some findings may resonate with men's experiences, this study is limited to an analysis of women's experiences of ageing. This reflects the inclusion of gender as a sensitizing concept within the research design and supports evidence regarding gendered ageing (e.g. Bowman et al., 2017).

\section{Conclusion}

This study elaborates an approach to intersectional reflexivity that sheds light on the experiences of older women in transiting to and realizing self-employment. It demonstrates the value of this approach for understanding agency by highlighting how older women navigate their concerns in relation to gendered ageing. Self-employment can thus be a powerful means by which older women have the possibility of achieving forms of expression, learning and solidarity in their situated context. We invite future, longitudinal analyses of self-employment among older women to provide evidence of the emotional and material implications of the transition, and further identify how forms of intersectional reflexivity shape experiences and business sustainability within the population of older women's enterprises. Such evidence would add additional detail to the insights presented here on the age-work exclusion older women experience and further distil indicators of the conditions and returns of self-employment for older women. The illustrative evidence of our arguments is specific to the UK context and similarly economically developed countries. Exploring the extent to which the experiences of self-employed older women vary in other contexts, such as transitional or developing economies, and its implications, would be fruitful.

The promotion of self-employment for older women, included among the numbers of 'missing entrepreneurs', is a policy priority internationally (OECD, 2019b). We suggest that a more informed policy debate that fully acknowledges the barriers facing older women and the diversity of the 'entrepreneur' is required. We concur with Lewis and Walker (2011) that self-employment should not be viewed as a 'policy panacea'. Our findings have demonstrated why an important part of addressing these concerns is to consider the position of those who are excluded or marginalized in intersectional terms. Further, to achieve truly emancipatory ends that extend beyond purely economic concerns, our analysis argues for intersectional reflexivity and its potential for coalition activism and alliance. We argue against top-down policy solutions and for prioritizing older women being supported to work together and with appropriate agencies to diagnose their situation, identify their interests and design their entrepreneurial projects. Such a shift stands to make a meaningful impact by bolstering strategic interventions with the potential to improve inclusivity among under-represented and disadvantaged groups. Informed by a critical position, our study demonstrates that understanding how older women negotiate ageing and its implications for self-employment remains particularly tense and intriguing.

\section{Acknowledgements}

We would like to thank Dimitria Groutsis for her constructive feedback on earlier versions of this article. Thanks also to the three anonymous reviewers and Uracha Chatrakul Na Ayudhya, the handling editor, for their diligence, very helpful suggestions and advice. An earlier version of the article was presented at the Academy of Management Conference 2019. 


\section{Funding}

The authors disclosed receipt of the following financial support for the research, authorship, and/ or publication of this article: British Academy/Leverhulme Small Research Grant, Grant/Award Number: SG160124.

\section{ORCID iD}

Elina Meliou (iD https://orcid.org/0000-0002-8912-3378

\section{References}

Acker J (2006) Inequality regimes: gender, class, and race in organizations. Gender \& Society 20(4): 441-464.

Ahl $\mathrm{H}$ and Marlow S (2012) Exploring the dynamics of gender, feminism and entrepreneurship: advancing debate to escape a dead end? Organization 19(5): 543-562.

Ainsworth S (2002) The 'feminine advantage': a discursive analysis of the invisibility of older women workers. Gender, Work \& Organization 9(5): 579-601.

Ainsworth S and Cutcher L (2008) Staging value and older women workers: when 'something more' is too much. International Journal of Work Organisation and Emotion 2(4): 344-357.

Ainsworth S and Hardy C (2008) The enterprising self: an unsuitable job for an older worker. Organization 15(3): 389-405.

Anthias F (2013) Hierarchies of social location, class and intersectionality: towards a translocational frame. International Sociology 28(1): 121-138.

Archer M (2003) Structure, Agency and the Internal Conversation. Cambridge: Cambridge University Press.

Archer M (2007) Making Our Way Through the World: Human Reflexivity and Social Mobility. Cambridge: Cambridge University Press.

Archer M (2012) The Reflexive Imperative in Late Modernity. Cambridge: Cambridge University Press.

Atkinson C, Ford J, Harding N, et al. (2015) The expectations and aspirations of a late-career professional woman. Work, Employment and Society 29(6): 1019-1028.

Bertaux D and Thompson PR (2006) Pathways to Social Class: A Qualitative Approach to Social Mobility. Piscataway, NJ: Transaction Publishers.

Bowman D, McGann M, Kimberley H, et al. (2017) Rusty, invisible and threatening: ageing, capital and employability. Work, Employment and Society 31: 465-482.

Calás MB, Smircich L and Bourne KA (2009) Extending the boundaries: reframing 'Entrepreneurship as social change' through feminist perspectives. The Academy of Management Review 34: 552-569.

Calasanti T (2005) Ageism, gravity, and gender: experiences of aging bodies. Generations 29(3): $8-12$.

Calasanti T and King N (2015) Intersectionality and age. In: Twigg J and Martin W (eds) Routledge Handbook of Cultural Gerontology. London: Routledge, 193-200.

Chamberlayne P, Rustin M and Wengraf T (2002) Biography and Social Exclusion in Europe. Bristol: The Polity Press.

Choroszewicz M and Adams TL (2019a) Gender and age in the professions: intersectionality, meta-work, and social change. Professions and Professionalism 9(2): 1-13.

Choroszewicz M and Adams TL (2019b) Introduction: themes, objectives and theoretical perspectives. In: Choroszewicz M and Adams TL (eds) Gender, Age and Inequality in the Professions. Abingdon: Routledge, 3-22. 
Clegg S (2006) The problem of agency in feminism: a critical realist approach. Gender and Education 18(3): 309-324.

Cook PS (2018) Continuity, change and possibility in older age: identity and ageing-as-discovery. Journal of Sociology 54(2): 178-190.

Crenshaw K (1991) Mapping the margins: identity politics, intersectionality, and violence against women. Stanford Law Review 43(6): 1241-1299.

Crossley N (2006) Reflexive Embodiment in Contemporary Society: The Body in Late Modern Society. Berkshire: McGraw-Hill Education.

De Clercq D and Voronov M (2009) Toward a practice perspective of entrepreneurship: entrepreneurial legitimacy as habitus. International Small Business Journal 27(4): 395-419.

Denissen AM (2010) The right tools for the job: constructing gender meanings and identities in the male-dominated building trades. Human Relations 63(7): 1051-1069.

Department for Work and Pensions (DWP) (2017) Automatic Enrolment Review 2017: Maintaining the Momentum. London: DWP. Available at: https://www.gov.uk/government/publications/ automatic-enrolment-review-2017-maintaining-the-momentum (accessed 11 February 2020).

Dumas A and Laberge S (2005) Social class and ageing bodies: understanding physical activity in later life. Social Theory and Health 3(3): 183-205.

Duncan C and Loretto W (2004) Never the right age? Gender and age-based discrimination in employment. Gender, Work \& Organization 11(1): 95-115.

Elder GH (1985) Life Course Dynamics: Trajectories and Transitions, 1968-1980. Ithaca, NY: Cornell University.

Elder GH, Johnson MK and Crosnoe R (2003) The emergence and development of life course theory. In: Mortimer JT and Shanahan MJ (eds) Handbook of the Life Course. Boston, MA: Springer, 3-19.

Hallier J (2001) Greenfield recruitment and selection. Personnel Review 3(30): 331-351.

Hodges J (2012) The transition of midlife women from organisational into self-employment. Gender in Management: An International Journal 3(27): 186-201.

Jayawarna D, Rouse J and Macpherson A (2014) Life course pathways to business start-up. Entrepreneurship \& Regional Development 26(3-4): 282-312.

Jones RG (2010) Putting privilege into practice through 'intersectional reflexivity': ruminations, interventions, and possibilities. Reflections: Narratives of Professional Helping 3: 122-125.

Jyrkinen M and McKie L (2012) Gender, age and ageism: experiences of women managers in Finland and Scotland. Work, Employment and Society 26(1): 61-77.

Knight M (2016) Race-ing, classing and gendering racialized women's participation in entrepreneurship. Gender, Work \& Organization 23(3): 310-327.

Kohli M (2007) The institutionalization of the life course: looking back to look ahead. Research in Human Development 4(3): 253-271.

Krekula C (2007) The intersection of age and gender: reworking gender theory and social gerontology. Current Sociology 55(2): 155-171.

Lather P (1991) Getting Smart: Feminist Research and Pedagogy With/in the Postmodern. New York: Routledge.

Lévesque M and Minniti M (2006) The effect of aging on entrepreneurial behaviour. Journal of Business Venturing 21: 177-194.

Lewis K and Walker EA (2011) Self-employment: policy panacea for an ageing population? Small Enterprise Research 18: 143-151.

McCall L (2005) The complexity of intersectionality. Signs 30(3): 1771-1800.

McGregor J (2018) Older women and career development: double (triple) jeopardy plus or endless opportunities? In: Broadbridge AM and Fielden SL (eds) Research Handbook of Diversity and Careers. Cheltenham: Edward Elgar Publishing, 60-74. 
McKie L, Biese I and Jyrkinen M (2013) 'The best time is now'! The temporal and spatial dynamics of women opting into self-employment. Gender, Work \& Organization 20(2): 184-196.

McMullin JA and Cairney J (2004) Self-esteem and the intersection of age, class, and gender. Journal of Aging Studies 18(1): 75-90.

McMullin JA and Dryburgh H (2011) Gender, age and work in the new economy. In: McMullin JA (ed.) Age, Gender, and Work: Small Information Technology Firms in the New Economy. Vancouver, CA: UBC Press, 3-17.

Meliou E (2020) Family as a eudaimonic bubble: women entrepreneurs mobilizing resources of care during persistent financial crisis and austerity. Gender, Work \& Organization 27(2): $218-235$.

Moore S (2009) 'No matter what I did I would still end up in the same position': Age as a factor defining older women's experience of labour market participation. Work, Employment and Society 23(4): 655-671.

Neumark D, Burn I and Button P (2019) Is it harder for older workers to find jobs? New and improved evidence from a field experiment. Journal of Political Economy 127(2): 922-970.

Office for National Statistics (ONS) (2018) Civil Service Statistic. London: ONS. Available at: https://www.ons.gov.uk/employmentandlabourmarket/peopleinwork/publicsectorpersonnel/ bulletins/civilservicestatistics/2018 (accessed 11 February 2020).

OECD (2019a) Ageing and Employment Policies. Paris: OECD Publishing. Available at: https:// www.oecd.org/employment/ageingandemploymentpolicies.htm (accessed 11 February 2020).

OECD (2019b) The Missing Entrepreneurs 2019: Policies for Inclusive Entrepreneurship. Paris: OECD Publishing. Available at: https://www.oecd.org/industry/the-missing-entrepreneurs43c2f41c-en.htm (accessed 2 October 2020).

Özbilgin M and Woodward D (2004) 'Belonging' and 'otherness': sex equality in banking in Turkey and Britain. Gender, Work \& Organization 11(6): 668-688.

Perenyi A, Zolin R and Maritz A (2018) The perceptions of Australian senior entrepreneur on the drivers of their entrepreneurial activity. International Journal of Entrepreneurial Behavior and Research 24(1): 81-103.

Radl J (2012) Too old to work, or too young to retire? The pervasiveness of age norms in Western Europe. Work, Employment and Society 26(5): 755-771.

Risman B (1998) Gender Vertigo: American Families in Transition. New Haven, CT: Yale University Press.

Sevenhuijsen S (2000) Caring in the third way: the relation between obligation, responsibility and care in Third Way discourse. Critical Social Policy 20(1): 5-37.

Spedale S, Coupland C and Tempest S (2014) Gendered ageism and organizational routines at work: the case of day-parting in television broadcasting. Organization Studies 35(11): 1585-1604.

Spence C, Carter C, Belal A, et al. (2016) Tracking habitus across a transnational professional field. Work, Employment and Society 30(1): 3-20.

Tatli A and Özbilgin MF (2012) An emic approach to intersectional study of diversity at work: a Bourdieuan framing. International Journal of Management Reviews 14(2): 180-200.

Thorpe R (2018) Ageing and the presentation of self: women's perspectives on negotiating age, identity and femininity through dress. Journal of Sociology 4(2): 203-213.

Tomlinson F and Colgan F (2014) Negotiating the self between past and present: narratives of older women moving towards self-employment. Organization Studies 35(11): 1655-1675.

Walker EA and Webster BJ (2007) Gender, age and self-employment: some things change, some stay the same. Women in Management Review 22(2): 122-135.

Warhurst C, Van den Broek D, Hall R, et al. (2012) Great expectations: gender, looks and lookism at work. International Journal of Work Organisation and Emotion 5(1): 72-90. 
Wright T (2016) Women's experience of workplace interactions in male-dominated work: the intersections of gender, sexuality and occupational group. Gender, Work \& Organization 23(3): 348-362.

Elina Meliou is Senior Lecturer in Organisational Behaviour at Aston Business School. Elina's research projects focus on diversity and inclusion at work. Her research has appeared in journals such as Human Relations, Gender, Work \& Organisation, International Small Business Journal, and Work, Employment and Society.

Oliver Mallett is Associate Professor in Work and Employment at University of Stirling Management School. Oliver's current research project focuses on government policy and other forms of influence on small businesses and their owner-managers. In particular, Oliver's research is examining the provision and use of formal and informal business support.

Date submitted April 2019

Date accepted October 2020 